\title{
Human papillomaviruses and cervical neoplasia. II. Interaction of HPV with other factors
}

\author{
C S Herrington
}

\begin{abstract}
Introduction
The frequency with which human papillomavirus (HPV) sequences are found in the general population, the prospective demonstration of a high rate of regression of infections with "high risk" HPV types, and the occurrence of HPV negative tumours suggest that HPV infection alone is not responsible for cervical neoplasia. Several co-factors have been identified by epidemiological means and others suggested by experimental observation (table): analysis of these co-factors gives insight not only into the other steps involved in carcinogenesis, but also into the possible mechanism of action of HPVs.
\end{abstract}

\section{Oncogenes}

IN VITRO STUDIES

Studies of the cooperation between HPV genes and oncogenes in the transformation of normal cells have been performed using both rodent and human cells. The HPV 16 early (E) 6 and E7 genes, under the control of a heterologous promoter, can immortalise primary baby rat kidney (BRK) cells and, with the cooperation of the activated $\mathrm{H}$-ras gene, transform them such that they are tumourigenic in syngeneic animals. ${ }^{1}$ Using the same (BRK) cells, it was also shown that the E7 gene, controlled by the SV40 promoter, has transforming ability in association with activated $\mathrm{H}-$ ras -1 and that this function is conferred by the E7 gene product. ${ }^{2}$ These studies were extended to other HPV types (HPV 6, 11, 18, 31 , and 33) and showed that HPV 16, 18, 31, and 33, but not HPV 6 and 11, were capable of cooperating with activated $\mathrm{H}$-ras in the transformation of BRK cells. ${ }^{3}$ The E7 genes from HPV 6 and 11 were subsequently shown to be capable of cooperating with H-ras-1 but only under the control of a strong promoter and with an efficiency 50 to 100 -fold lower than that of the HPV 16 E7 gene. ${ }^{4}$ Continued E7 gene expression was required for maintenance of the malignant phenotype ${ }^{5}$ and this is consistent with in vivo evidence regarding retention of the E7 gene in carcinoma derived cell lines. Investigation of HPV 16 early genes under the control of their own promoter showed that they cooperated with activated $\mathrm{H}$-ras but only if expression was promoted by glucocorticoid. ${ }^{6}$ This is consistent with the
Other factors involved in HPV associated cervical neoplasia

Oncogenes

Tumour suppressor genes

Chromosome aberrations

"Cellular interfering factor"

Hormones

Smoking

Other infectious agents

Cytokines and growth factors

Host immune response

observation that the upstream regulatory region of HPV 16 contains a glucocorticoid responsive enhancer element. ${ }^{7}$ This element is independent of E2 protein and hence will operate where viral integration disrupting the E2 gene has occurred.

HPV 16, 18, 31, and 33 but not HPV 6, under the control of a heterologous promoter, can cooperate with c-fos but not c-myc, v-fms, v-mos, c-src, or p53. ${ }^{6}$ However, the E7 gene product is not as efficient as the whole early gene region in transforming primary cultures in association with activated $\mathrm{H}$-ras, suggesting that other viral early genes are required for efficient transformation.

A modification of the two step approach used for the study of rodent cells has been applied to primary human cells. ${ }^{8}$ These cells were transfected with HPV 16 in association with a strong promoter with or without activated $\mathrm{H}$-ras. In both circumstances the life span of the cells was extended but, after treatment with HPV 16 alone, the cells remained diploid with normal morphology. When activated $\mathrm{H}$-ras was also transfected, the cells became aneuploid, with a modal chromosome number of 85-88, were morphologically more refractile, and became independent of serum with an enhanced growth rate. In the absence of activated H-ras the cells were not tumourigenic, whereas after co-transfection, benign tumour nodules were produced. More specifically, cytogenetic analysis of co-transfected cells showed that translocations involving chromosomes 1 and 11 (particularly $t(1: 11$ ) (q12:q23)) were common. This observation is of relevance in the light of the localisation of $\mathrm{H}$-ras-1 to chromosome 11 and the postulated role of chromosome 11 in cervical neoplasia.

These studies show that HPV sequences induce immortalisation and are capable of cooperation with known oncogenes in vitro. 
Moreover, these observations are consistent with the epidemiological suggestion that HPV infection is an early event which is not sufficient for cellular transformation.

\section{ANALYSIS OF TUMOURS}

Rearrangement or amplification (up to 185fold), or both, of c-myc has been described in cervical carcinomas, ${ }^{9}$ in lesions with and without HPV 16 sequences. This, however, is not a consistent finding. ${ }^{10}$ Correlation between amplification of both c-myc and H-ras-1 and advanced tumour stage, and between elevated c-myc expression and poor prognosis of early cervical carcinomas has been shown. ${ }^{11} 12$ Analysis of the $\mathrm{H}$-ras- 1 gene has revealed loss of heterozygosity in $36 \%$ of tumours, $90 \%$ of which contained HPV 16 or 18 DNA. Mutations in codon 12 of the H-ras- 1 gene were identified in $2 \%$ of early and $24 \%$ of advanced tumours. ${ }^{13}$ Of the tumours which had a mutation, $40 \%$ had lost the other $\mathrm{H}$-ras- 1 allele. In the same series $100 \%$ of tumours with a mutation showed either overexpression or amplification of the c-myc gene. This is consistent with involvement of establishment and transforming genes in phenotypic transformation. However, other studies have failed to find $\mathrm{Ki}$-ras gene mutation in primary cervical carcinomas. ${ }^{14}$

\section{Tumour suppressor genes}

\section{THE p53 GENE}

The $\mathrm{p} 53$ gene product promotes growth arrest and cell death by apoptosis in response to genotoxic insults and has been termed the "guardian of the genome". Defective function of this protein by either mutation or inactivation may lead to the persistence and replication of genetic defects and therefore it would not be surprising if this gene were of central importance in the neoplastic process.

The E6 proteins of HPV 16 and 18 bind to p53 protein, albeit with different affinities. ${ }^{15}$ It has been suggested that binding of these proteins in vivo may alter cellular regulatory functions such that proliferation and transformation occur secondary to inactivation of $\mathrm{p} 53$ activity. Binding of $\mathrm{p} 53$ by E6 protein of HPV 16 , but not that of HPV 6 , leads to accelerated degradation of the complex via the ubiquitin pathway in vivo. ${ }^{16}$ This degradation is accelerated by the presence of a third protein, E6 associated protein (E6-AP) ${ }^{17}$ and the demonstration of co-localisation of $\mathrm{p} 53$ and E6 proteins in the cytoplasm by confocal microscopy suggests that binding and degradation prevent the p53 protein exerting its effect in the cell nucleus. ${ }^{18}$

The demonstration that HPV positive cell lines possessed a wild-type p53 gene, whereas in HPV negative cell lines the gene was mutated, led to the hypothesis that $\mathrm{p} 53$ mutation and inactivation by complexing with E6 protein are mutually exclusive events. ${ }^{19}$ This hypothesis has recently been tested using cervical carcinomas with conflicting results and p53 mutations have been demonstrated in HPV positive tumours. ${ }^{20}$ Studies using immunostaining have also produced conflicting results, with several workers reporting staining of the basal layers of inflammatory cervical lesions, condylomata, and low grade cervical intraepithelial neoplasia (CIN), and p53 positivity of HPV positive tumours. However, the equation of p53 immunostaining with p53 gene mutation is unlikely to be valid and these studies should be interpreted with caution. ${ }^{21}$ Nevertheless, the coexistence of p53 mutations and HPV infection does not preclude a role for $\mathrm{E} 6 / \mathrm{p} 53$ binding in cervical carcinogenesis as p53 mutation may occur as a secondary event in these tumours. The demonstration of p53 mutation in metastases from an HPV positive carcinoma would support this possibility, ${ }^{22}$ suggesting that acquisition of further genetic abnormalities may be involved in tumour progression.

Mechanistically, the immortalisation of cells by HPV 16 E6/E7 abrogates the increase in $\mathrm{p} 53$ expression and reduction in DNA synthesis induced by actinomycin $\mathrm{D}^{23}$ and HPV 18 E6 inhibits p53 dependent enhancement of transcription after ultraviolet irradiation. ${ }^{24}$ Similarly, the presence of E6 from HPV 16, but not that from HPV 6, reduced the ability of p53 to stimulate transcription and this property is also possessed by mutant $\mathrm{p} 53 .{ }^{25}$ Thus, p53 mutation and inactivation are in some respects biologically similar. However, mutant p53 has immortalising ability but does not possess the transactivating or transforming functions of E6. ${ }^{26}$ Conversely, it is theoretically possible for the cell to overcome the effects of $\mathrm{E} 6$ on $\mathrm{p} 53$ by synthesising more p 53 protein, whereas the effect of a p53 mutation is irreversible. However, the failure of artificially increasing wild-type p53 protein in HPV immortalised cells to reverse the immortalisation process does not support this contention. ${ }^{27}$ Nevertheless, cooperation of HPV 18 E6 with c-myc and H-ras appears to be necessary for the complete functional inactivation of wild-type p53 in NIH-3T3 cells, suggesting that other genetic events are required. ${ }^{28}$

A p53 mutation cannot always be demonstrated in HPV negative tumours ${ }^{29}$ and, although it is important to exclude the possibility that these tumours contain uncharacterised HPV types not detected by the HPV assay used, it seems likely that mechanisms other than p53 mutation/inactivation are important in some tumours.

THE RETINOBLASTOMA GENE

The E7 proteins of HPV 16 and 18 bind to the hypophosphorylated form of the product of the retinoblastoma gene ( $\mathrm{Rb})$, the prototype tumour suppressor gene $\mathrm{e}^{30}$; this binding leads to dissociation of $\mathrm{Rb}$ from the transcription factor E2F. The E7 protein also binds to histone $\mathrm{H} 1$ kinase and to p107, ${ }^{31}$ emphasising its potential to interfere with cell cycle control.

Activated oncogenes can therefore cooperate with HPV sequences in the transformation of primary human cells and HPV infection with "high risk" types abrogates the function 
of well characterised tumour suppressor genes. Indeed, a single HPV infection is equivalent to multiple genetic events, early genes having dominant transforming function as well as the ability of E6 and E7 to bind to p53 and $\mathrm{Rb}$ proteins being functionally equivalent to the loss of both alleles. These actions may explain the strength of the association of cervical neoplasia with HPV infection.

\section{Chromosome aberrations}

Chromosome abnormalities, particularly of chromosomes 1 and 11, can be induced in human cells by cotransfection with HPV DNA and activated $\mathrm{H}-\mathrm{ras}^{8}$ and in raft cultures. ${ }^{32}$ Cytogenetic analysis of cervical tumours has shown that chromosomes 1, 3, 11 , and 17 are often abnormal ${ }^{33}$ and transformation is associated with non-random aberrations involving chromosomes $1,11,19$, and $20 .{ }^{34}$ It is possible that changes in gene dosage by chromosome loss, duplication, or rearrangement following induction of aneuploidy might lead to inactivation of cellular tumour suppressor genes such as p53 or activation of oncogenes. Induction of aneuploidy by HPV 16 sequences suggests that viral DNA may play a part in this process and the observation that immortalisation of keratinocytes by the E6 and E7 genes of HPV 16 and 18 leads to expression of mitotic regulatory proteins, such as p34cdc2 and cyclin A, suggests a possible mechanism. ${ }^{35}$

\section{Cellular interfering factor}

The study of HeLa cells/fibroblast hybrids has led to the hypothesis that cellular genes which suppress the function of viral transformation genes exist in normal human cells; somatic cell hybrid experiments have localised this function to chromosome 11 . This has been termed cellular interfering factor (CIF) and has been postulated to act by suppression of E6/E7 expression in vivo. ${ }^{36}$ Both tumourigenic and non-tumourigenic $\mathrm{HeLa}$ cell/fibroblast hybrids express HPV 18 E6/E7 messenger RNA (mRNA) to a high level in vitro but this expression is inhibited in vivo only in nontumourigenic hybrids. ${ }^{37}$ This is further evidence for the existence and role of CIF. However, no such factor has been identified as yet.

\section{Hormones}

It has been demonstrated experimentally that the upstream regulatory region of HPV 16 contains a glucocorticoid regulatory element. ${ }^{7}$ This element permits E2 independent early gene transcription. Therefore, steroid hormones may enhance viral transcription in vivo, as has been shown for oestrogens in $\mathrm{SiHa}$ cells. ${ }^{38}$ Conversely, progestagens extracted from oral contraceptive tablets were found to cooperate with H-ras-1 and HPV 16 in the transformation of primary BRK cells, ${ }^{39}$ while oestrogens had no effect. Cell lines produced in this way were capable of producing tumours in syngeneic animals. Therefore, there is experimental evidence for endocrine modulation of HPV infection in the genesis of cervical neoplasia.

\section{Smoking}

There are limited data regarding the interaction of smoking and HPV infection, but the finding of reduced numbers of Langerhans' cells in cervical epithelium in smokers suggests that reduced presentation of viral antigen may occur, resulting in viral persistence. ${ }^{40}$ The prevalence of HPV is related to smoking history and there is a dose response relationship. ${ }^{41}$ Moreover, among women with HPV $16 / 18$ infection, the relative risk of invasive cancer is greater in those who smoke than in those who do not. ${ }^{42}$ Polycyclic hydrocarbon DNA adducts, which may lead to induction of mutations, have been shown to be more frequent in biopsy specimens from smokers than in those from non-smokers. ${ }^{43}$ Carcinogens present in smoke may therefore act alone or in concert with HPV.

\section{Other infectious agents}

There is little evidence for interaction between HPV and other agents except HIV and herpes viruses. Epstein-Barr virus (EBV) can be identified within both lymphocytes and epithelial cells in invasive squamous cell carcinoma (ISCC) ${ }^{44}$ However, the relevance of the presence of EBV, and whether it is capable of interacting mechanistically with HPV, has yet to be established. Analysis of CIN III and ISCC has revealed HPV 16 in six of eight herpes simplex virus (HSV) containing lesions. ${ }^{10}$ However, the simultaneous presence of both viruses does not equate with their interaction in cervical carcinogenesis. None the less, HSV can alter the growth of cells immortalised by HPV 16/18. ${ }^{45}$ Recently, it has been shown that human herpes virus 6 can infect cervical epithelial cells and is capable of transactivating expression of E6 and E7 genes. ${ }^{46}$

\section{Cytokines and growth factors}

A wide variety of cytokines are produced by immune effector cells. ${ }^{47}$ There are few in vivo studies of cervical lesions although interferons have been used successfully in the treatment of invasive cervical carcinoma. ${ }^{48}$ In vitro interferons $a, \beta$, and $\gamma$ reduce HPV 16 E6 gene transcription in the cervical carcinoma derived cell line $\mathrm{SiHa}^{49}$ Leukoregulin and interferon- $\gamma$ can inhibit HPV 16, 18, and 33 E6/E7 gene transcription in immortalised cell lines with an associated reduction in cell proliferation, but interferon- $\alpha$ has no effect. ${ }^{50}$ Similarly, transforming growth factor $\beta$ inhibits production of both HPV 16 and 18 E6 and E7 genes in HPV transformed keratinocytes. ${ }^{51}$

The E5 gene can cooperate with ligand stimulated epidermal growth factor receptor 
and, to a lesser extent, with platelet derived growth factor receptor in cellular transformation; this is associated with increased signal transduction and upregulation of c-fos gene transcription. ${ }^{52}$

Cytokines and growth factors are therefore capable of modulating the cellular effects of HPV and may be important in the control of HPV infection by both immune and nonimmune mechanisms.

\section{The immune response to HPV and the role of immunosuppression}

The response to viral infection is generally cell mediated and although antibodies to viral proteins derived from early and late genes are detectable in patients with HPV infection, their presence does not correlate with clinical behaviour. ${ }^{53}$ The importance of cell mediated immunity is suggested by the high incidence of viral warts in immunosuppressed patients and by the observation that spontaneous regression of warts is associated with marked infiltration by lymphocytes and macrophages.

\section{SYSTEMIC IMMUNITY}

It has emerged recently that the prevalence of HLA DQw3 is greater in patients with cervical carcinoma than in the control population. $^{54}$ This suggests that some class II HLA antigens may be associated with increased susceptibility to cervical carcinoma, although this association was not found by others. ${ }^{55}$ There are, however, some data showing that the association is stronger between HLA DQw3 and HPV infection than between it and the degree of $\mathrm{CIN}$ or invasive carcinoma, ${ }^{56}$ suggesting that patients who are HLA DQw3 positive may be at greater risk of cervical neoplasia because of a reduced ability to clear HPV infection.

An increased incidence of $\mathrm{CIN}$ has been described in patients who have received renal transplants: in one study mean lag time to condylomatous change was 22.4 months and to CIN or invasive cancer 38.0 months. ${ }^{57}$ The transient immunosuppression which occurs in pregnancy is associated with an increased incidence of genital warts and CIN lesions, and a higher prevalence of HPV in cervical smears. ${ }^{58}$

More recently, an increased risk of cervical neoplasia has been noted in patients infected with HIV and the severity and duration of viral warts are similarly increased. The prevalence of HPV is increased in HIV positive patients, particularly if they are not immunocompetent as assessed by CD4 count $^{59}$; HPV associated epithelial abnormalities are more common in immunosuppressed HIV positive patients. Interaction between HPV and HIV has been demonstrated in vitro with the tat-1 protein of HIV capable of enhancing E2 dependent HPV 16 transcription ${ }^{60}$ : this provides a potential mechanism for interaction between these agents and suggests that the interaction may occur in two separate waysthat is, by immunosuppression and by direct alteration of gene transcription.

\section{LOCAL IMMUNITY}

Immune effector cells are demonstrable in the normal cervix and in association with CIN and invasive carcinoma. It has been noted that the number of Langerhans' cells in the cervical epithelium is reduced in smokers ${ }^{40}$ and in association with both wart virus infection (WVI) and CIN. ${ }^{61}$ This reduction is seen both with low and high risk HPV types, but is most apparent in low grade lesions with the density of Langerhans' cells increasing with the CIN grade. ${ }^{62}$ Langerhans' cell number is also reduced in HIV positive patients and correlates with $\mathrm{CD} 4 / \mathrm{CD} 8$ counts and hence the degree of immunosuppression. ${ }^{63}$ Similarly, $T$ cell numbers are reduced in patients with WVI and CIN, suggesting a local defect in cell mediated immunity. The aetiological role of these alterations, and whether they are primary or secondary, has yet to be determined.

Immunological recognition of viral antigens is governed by HLA class I and II antigen $s^{64}$ and, although complete loss is seen only rarely in preinvasive disease, invasive carcinomas may show complete or heterogeneous loss of HLA class I antigen expression. Patients with low stage tumours which show downregulated HLA class I antigen expression have a worse prognosis and this may be related to metastatic capability. Conversely, cervical carcinoma cells, but not normal cervical epithelial cells, express HLA class II antigens. Upregulation occurs independently of the presence of HPV DNA or RNA but is associated with the CIN grade. These cells resemble antigen presenting cells phenotypically and, therefore, may be involved in immune surveillance. This assertion is supported by the observation that $\mathrm{T}$ cells, natural killer cells, and macrophages are present in greater numbers in tumours which express class II antigens. ${ }^{65}$

\section{HPV infection and clinical practice}

The importance of HPV in the genesis of cervical neoplasia suggests that diagnosis of a particular HPV infection would dictate a particular clinical outcome and hence be useful in patient management. However, HPV infection occurs early and is neither necessary nor sufficient for oncogenesis. Indeed, HPV negative cervical carcinomas appear to have a worse prognosis than HPV positive ones. ${ }^{12}$ There are however several possible areas in which HPV analysis may be of clinical value, two of which will be highlighted here.

\section{CERVICAL SCREENING}

The principles of screening involve the application of a simple, cheap, effective test to a high risk population. The evidence that CIN lesions are a precursor to invasive cancer forms the basis of the screening programme, the premise being that the detection and treatment of these lesions prevents progression to invasive disease. The rationale behind screening the whole female population is that no individual epidemiological risk factor is of sufficient magnitude to warrant the identification of subgroups of women. The relative risk of 
women with high risk HPV infection is great enough to prompt consideration of HPV testing as an adjunct to cytology. However, it is important to appreciate that the "disease" being screened for is dyskaryosis and the objective is to prevent cervical cancer. This is currently being achieved by cytological surveillance. Any alternative approach must be formally compared with this in terms of both efficacy and cost-effectiveness. Moreover, unless there is an absolute link between HPV infection and invasive disease (which does not appear to be the case), a HPV based screening programme would miss a proportion of cases.

\section{PATIENTS WITH LOW GRADE CYTOLOGICAL ABNORMALITIES}

The combination of more carefully controlled epidemiological studies and use of semiquantitative methods for the detection of HPV in cytological material has prompted a re-evaluation of the role of HPV for the determination of those patients with low grade cytological abnormalities who either have or will develop a high grade lesion. Persistent and high copy number HPV infections appear to be important in this situation and are associated with high grade lesions (see Part I). If these findings are confirmed, demonstration of persistent high risk HPV types, particularly in high copy number, may imply an increased risk of either current or future high grade CIN. This would establish a role for HPV testing, particularly in patients with low grade smear abnormalities. However, the success of this approach is dependent not only on the sensitivity of the test employed but also on the population being studied. Clinical usefulness will require formal testing.

\section{Conclusions}

Experimental evidence linking HPV to cervical neoplasia is strong. The differential effects of high and low risk viruses can be partially explained and the epidemiological suggestion of interaction between HPV and other factors has some experimental basis. With increasing knowledge, particularly from the study of systems such as collagen raft culture and transgenic mice and the refinement of techniques for HPV detection in clinical material, it is likely that the role of HPV will be confirmed and the mechanism of its involvement further defined. The role of host immunity is now thought to be of more importance, while the role of cytokines and inflammatory cells in the control of HPV infection is an area which warrants further study. Indeed, a recent hypothesis of cervical carcinogenesis suggests that three separate groups of events occur: the abrogation of growth control genes-for example, p53 and $\mathrm{Rb}-1$, leading to low grade lesions; interference with host genes involved in the control of viral gene transcription leading to high grade lesions; and escape from immune attack leading to invasive disease ${ }^{66} \mathrm{HPV}$ infection holds a central position in this model and is unique in its ability to both abrogate host gene function and have transforming and transactivating function at several sites simultaneously. Thus, a single HPV infection represents several genetic "hits" and therefore, under appropriate circumstances, may contribute several components of the neoplastic process.

I thank Professor JO'D McGee for help, support and encouragement. The financial support of the Cancer Research
Campaign (UK) and Oxford Regional Health Authority is gratefully acknowledged.

1 Matlashewski G, Osborn K, Murray A, Banks L, Crawford L. Transformation of mouse fibroblasts with HPV type L. Transformation of mouse fibroblasts with HPV type 16 DNA usin

2 Phelps W, Howley PM. Transcriptional transactivation of by the human papillomavirus type $16 \mathrm{E} 2$ gene product. $\mathcal{F}$ Virol 1987;61:1630-8.

3 Storey A, Pim D, Murray A, Osborn K, Banks L, Crawford $\mathrm{L}$. Comparison of the in vitro transforming 1988;7:1815-20.

4 Storey A, Almond N, Osborn K, Crawford L. Mutations of the human papillomavirus type $16 \mathrm{E} 7 \mathrm{gene}$ that affect of the human papillomavirus type 16 E7 gene that affect transformation, transactivation and phosphory

5 Crook T, Morgenstein J, Crawford L, Banks L. Continued expression of HPV16 E7 protein is required for maintenance of the transformed phenotype of cells transformed by HPV16 plus EJ-ras. EMBO $\mathcal{F} 1989 ; 8: 513-9$.

6 Crook T, Storey A, Almond N, Osborn K, Crawford L. Human papillomavirus type 16 cooperates with activated ras and fos oncogenes in the hormone-dependent transformation of primary mouse cells. Proc Natl Acad Sci USA 1988;85:8820-4.

7 Gloss B, Bernard HU, Seedorf K, Klock G. The upstream regulatory region of the human papilloma virus-16 conregulatory region of the human papilloma virus-16 contains an E2 protein-independent enhancer which is speglucocorticoid hormones. EMBO $₹$ 1987;6:3735-43.

8 Matlashewski G, Osborn K, Banks L, Stanley M, Crawford L. Transformation of primary human fibro blast cells with human papillomavirus type 16 DNA and EJ-ras. Int $\mathcal{f}$ Cancer 1988;42:232-8.

9 Gariglio P, Ocadiz R, Sauceda R. Human papillomavirus DNA sequences and c-myc oncogene alteration in uterine cervix carcinoma. Cancer Cells 1987;5:343-8.

10 Di Luca D, Costa S, Monini P, Rotola A, Terzano P, Savioli A, et al. Search for human papillomavirus, herpes simplex and c-myc oncogene in human genital tumours. Int $₹$ Cancer 1989;43:570-7.

11 Iwasaka T, Yokoyama M, Oh-uchida M, Matsuo N, Hara $\mathrm{K}$, Fukuyama $\mathrm{K}$, et al. Detection of human papillomavirus genome and analysis of expression of c-myc and Ha-ras oncogenes in invasive cervical carcinomas. Gynecol Oncol 1992;46:298-303.

12 Riou G, Le MG, Favre M, Jeannel D, Bourhis J, Orthi G. Human papillomavirus-negative status and c-myc gen overexpression: independent prognostic indicators of distant metastasis for early-stage invasive cervical cancers. F Natl Cancer Inst 1992;84:1525-6.

13 Riou G, Barrois M, Sheng Z-M, Duvillard P, L'homme C. Somatic deletions and mutations of c-Ha-ras gene in human cervical cancers. Oncogene 1988;3:329-33.

14 Falcinelli C, Luzi P, Alberti P, Cosmi EV, Anceschi MM. Human papilloma virus infection and $\mathrm{Ki}$-ras oncogene Human papilloma virus infection and $\mathrm{Ki}$-ras oncogene in parafin-embedded squamous

15 Werness BA, Levine AJ, Howley PM. Association of human papillomavirus types 16 and 18 E6 proteins with p53. Science 1990;248:76-9.

16 Hubbert NL, Sedman SA, Schiller JT. Human papillomavirus type $16 \mathrm{E} 6$ increases the degradation rate of p 53 in human keratinocytes. $\mathcal{F}$ Virol 1992;66:6237-41.

17 Scheffner M, Huibregtse JM, Vierstra RD, Howley PM. The HPV-16 E6 and E6-AP complex functions as a ubiquitin-protein ligase in the ubiquitination of p53. Cell 1993;75:495-505.

18 Liang XH, Volkmann M, Klein R, Herman B, Lockett SJ. Co-localization of the tumor-suppressor protein p53 and human papillomavirus E6 protein in human
cinoma cell lines. Oncogene 1993;8:2645-52.

19 Crook T, Wrede D, Vousden KH. p53 point mutation in HPV negative human cervical carcinoma cell lines. Oncogene 1991;6:873-5.

20 Paquette RL, Lee YY, Wilczynski SP, Karmakar A, Kizaki $\mathrm{M}$, Miller CW, et al. Mutations of $\mathrm{p} 53$ and human papillomavirus infection in cervical carcinoma. Cancer 1993; 72:1272-80.

21 Lane S, Wells $M$. Human papillomaviruses, p53 and cervical neoplasia. f Pathol 1994;172:299-300.

22 Crook T, Vousden KH. Properties of p53 mutations detected in primary and secondary cervical cancers suggest mechanisms of metastasis and involvement of environmental carcinogens. EMBO $\mathcal{f} 1992 ; 11: 3935-40$.

23 Kessis TD, Slebos RJ, Nelson WG, Kastan MB, Plunkett BS, Han SM, et al. Human papillomavirus 16 E6 expression disrupts the p53-mediated cellular response to 
DNA damage. Proc Natl Acad Sci USA 1993;90: 3988-92.

24 Gu Z, Pim D, Labrecque S, Banks L, Matlashewski G. DNA damage induced p53 mediated transcription is inhibited by human papillomavirus type 18 E6. Oncogene 1994;9:629-33.

25 Hoppe SF, Butz K. Repression of endogenous p53 transactivation function in HeLa cervical carcinoma cells by human papillomavirus type $16 \mathrm{E} 6$, human $\mathrm{mdm}-2$, and mutant p53. ₹ Virol 1993;67:3111-7.

26 Sedman SA, Hubbert NL, Vass WC, Lowy DR, Schiller JT. Mutant p53 can substitute for human papillomavirus type $16 \mathrm{E} 6$ in immortalization of human keratinocytes but does not have E6-associated trans-activation or transforming activity. $\mathcal{F}$ Virol $1992 ; 66: 4201-8$.

27 Woodworth CD, Wang H, Simpson S, Alvarez SL Notario V. Overexpression of wild-type p53 alters Notario $V$. Overexpression of wild-type p53 alters growth and differentiation of normal human keratinocytes but not human papillomavirus-

28 Chen TM, Defendi V. Functional interaction of p53 with HPV18 E6, c-myc and H-ras in 3T3 cells. Oncogen 1992;7:1541-7.

29 Park DJ, Wilczynski SP, Paquette RL, Miller CW, Koeffler HP. p53 mutations in HPV-negative cervica carcinoma. Oncogene 1994;9:205-10.

30 Dyson N, Howley P, Munger K, Harlow E. The human papillomavirus-16 E7 oncoprotein is able to bind to the papillomavir

31 Davies R, Hicks R, Crook T, Morris J, Vousden $K$ Human papillomavirus type $16 \mathrm{E} 7$ associates with a histone $\mathrm{H} 1$ kinase and with 107 through sequences necessary for transformation. $\mathcal{F}$ Virol 1993;67:2521-8.

32 McCance DJ, Kopan R, Fuchs E, Laimins LA. Human papillomavirus type 16 alters human epithelial cell differentiation in vitro. Proc Natl Acad Sci USA 1988; 85:7168-73.

33 Teyssier JR. The chromosomal analysis of human solid tumours: a triple challenge. Cancer Genet Cytogenet 1989;37:103-25.

34 DiPaolo JA, Popescu NC, Alvarez L, Woodworth CD Cellular and molecular alterations in human epithelial cells transformed by recombinant human papillomavirus cells transformed by recombinant hum

35 Steinmann KE, Pei XF, Stoppler H, Schlegel R, Schlegel $R$. Elevated expression and activity of mitotic regulatory proteins in human papillomavirus-immortalized keratinocytes. Oncogene 1994;9:387-94.

36 zur Hausen $H$. Intracellular surveillance of persisting vira infections: human genital cancer results from deficien cellular control of papillomavirus gene expression. Lancet 1986;ii:489-91.

37 Bosch FX, Schwarz E, Boukamp P, Fusenig NE, Bartsch $D$, Zur Hausen $H$. Suppression in vivo of human papillomavirus type 18 E6-E7 gene expression in nontumorigenic HeLa $\times$ fibroblast hybrid cells. F Virol 1990; 64:4743-54.

38 Mitrani-Rosenbaum S, Tsvieli R, Tur-Kaspa R. Oestrogen stimulates differential transcription of human papillomavirus type 16 in $\mathrm{SiHa}$ cervical carcinoma cells. $\mathcal{F} \mathrm{Ge}$ Virol 1989;70:2227-32.

39 Pater A, Bayatpour M, Pater MM. Oncogenic transformation by human papillomavirus type 16 deoxyribonucleic acid in the presence of progesterone or progestins from oral contraceptives. Am $\mathcal{F}$ Obstet Gynaecol 1990;162: 1099-103.

40 Barton SE, Hollingworth A, Maddox PH, Edwards R Cuzick J, McCance DJ, et al. Possible cofactors in the etiology of cervical intraepithelial neoplasia. An immunopathologic study. $¥$ Reprod Med 1989;34:613-6.

41 Burger MP, Hollema H, Gouw AS, Pieters WJ, Quin WG. Cigarette smoking and human papillomavirus in patients with reported cervical cytological abnormality. patients with reported

42 Herrero R, Brinton LA, Reeves WC, Brenes MM, Tenorio $\mathrm{F}$, de Britton RC, et al. Invasive cervical cancer and smoking in Latin America. I Natl Cancer Inst 1989;81:205-11.

43 Simons AM, Phillips DH, Coleman DV. Damage to DNA in cervical epithelium related to smoking tobacco. $B M$ 1993;306:1444-8.

44 Landers RJ, O'Leary J, Crowley M, Healy I, Annis P, Burke L, et al. Epstein-Barr virus in normal, premalig nant and malignant lesions of the uterine cervix. $f$ Clin Pathol 1993;46:931-5.

45 Dhanwada KR, Garrett L, Smith $P$, Thompson KD, Doster A, Jones C. Characterization of human ker- atinocytes transformed by high risk human papillomavirus types 16 or 18 and herpes simplex virus type $2 . \mathcal{F}$ Gen Virol 1993;74:955-63.

46 Chen M, Popescu N, Woodworth C, Berneman Z, Corbellino M, Lusso P, et al. Human herpesvirus 6 infects cervical epithelial cells and transactivates human papillomavirus gene expression. $\mathcal{F}$ Virol 1994;68:1173-8. 47 Rees RC. Cytokines as biological response modifiers. $f$ Clin Pathol 1992;45:93-8.

48 Lippman SM, Kavanagh JJ, Paredes-Espinoza $M$ Delgadillo-Madrueño F, Paredes-Casillas P, Hong WK et al. 13-cis-retinoic acid plus interferon alpha-2a: highly active systemic therapy for squamous cell

49 De Marco F, Marcante ML. HPV-16 E6-E7 differential transcription induced in $\mathrm{SiHa}$ cervical cancer cell line by transcription induced in SiHa cervical cancer cell line by

50 Woodworth CD, Lichti U, Simpson S, Evans CH DiPaolo JA. Leukoregulin and gamma-interferon inhibit human papillomavirus type 16 gene transcription in human papillomavirus-immortalized human cervical cells. Cancer Res 1992;52:456-63.

51 Braun L, Durst M, Mikumo R, Crowley A, Robinson M Regulation of growth and gene expression in human papillomavirus-transformed keratinocytes by transforming growth factor-beta: implications for the control of papillomavirus infection. Mol Carcinog 1992:6:100-11.

52 Banks L, Matlashewski G. Cell transformation and the HPV E5 gene. Papillomavirus Rep 1993;4:1-4.

53 Jochmus I, Altmann A. Immune response to papillomaviruses: prospects of an anti-HPV vaccine. Papillomavirus Rep $1993 ; 4: 147-51$.

54 Wank R, Tomssen C. High risk of squamous cell carcinoma of the cervix for women with HLA-DQw3. Nature 1991;352:723-5.

55 Glew SS, Duggan-Keen M, Ghosh AK, Ivinson A, Sinnott $\mathrm{P}$, Davidson J, et al. Lack of association of HLA polymorphisms with human papillomavirus-related cervica cancer. Hum Immunol 1993;37:157-64.

56 Mehal WZ, Lo YM-D, Herrington CS, Evans MF, Papadopoulos MC, Odunsi K, et al. Role of human papillomavirus in determining the HLA associated risk of cervical icarcinogenesis. F Clin Pathol 1994;47: of cervical

57 Schneider A, Kay S, Lee HM. Immunosuppression as a high risk factor in the development of condyloma acuminatum and squamous neoplasia of the cervix. Acta Cytol 1983;27:220-4.

58 Rando RF, Lindheim S, Hasty L, Sedlacek TV, Woodland $M$, Eder C. Increased frequency of detection of human papillomavirus deoxyribonucleic acid in exfoliated cervical cells during pregnancy. $A m f$ Obstet Gynaecol 1989;161:50-5.

59 Johnson JC, Burnett AF, Willet GD, Young MA, Doniger $\mathrm{J}$. High frequency of latent and clinical human papillomavirus cervical infections in immunum papilohuman immunodeficiency virus-infected women. Obstet Guman immunodeficien 1992;79:321-7.

60 Vernon SD, Hart CE, Reeves WC, Icenogle JP. The HIV-1 tat protein enhances E2-dependent human papillomavirus 16 transcription. Virus Res 1993;27:133-45.

61 Morris HHB, Gatter KC, Sykes G, Casemore V, Maso DY. Langerhans' cells in human cervical epithelium: effects of wart virus infection and intraepithelial neoplasia. Br $\mathcal{F}$ Obstet Gynaecol 1983;90:412-20.

62 Morelli AE, Sananes C, Di PG, Paredes A, Fainboim L. Relationship between types of human papillomavirus and Langerhans' cells in cervical condyloma and intraepithelial neoplasia. Am f Clin Pathol 1993;99: intraepith.

63 Spinillo A, Tenti P, Zappatore R, De Seta F, Silini E Guaschino S. Langerhans' cell counts and cervical intraepithelial neoplasia in women with human immunodeficiency virus infection. Gynecol Oncol 1993;48 210-13.

64 Duggan-Keen M, Keating PJ, Cromme FV, Walboomers JMM, Stern PL. Alterations in major histocompatibility complex expression in cervical cancer: possible consequences for immunotherapy. Papillomavirus Rep 1994, 5:3-9.

65 Hilders CG, Houbiers JG, van Ravenswaay Claasen Hh, Veldhuizen RW, Fleuren GJ. Association between HLAexpression and infiltration of immune cells in cervical carcinoma. Lab Invest 1993;69:651-9.

66 zur Hausen H. Disrupted dichotomous intracellular control of human papillomavirus infection in cancer of the cervix. Lancet 1994;343:955-7. 